J. Clin. Chem. Clin. Biochem.

Vol. 27, 1989, pp. 873-877

(C) 1989 Walter de Gruyter \& Co.

Berlin - New York

\title{
Results of Comparative Determination of Morphine in Human Hair Using RIA and GC/MS
}

\author{
By $H$. Sachs
}

Institute of Forensic Medicine (Director: Prof. Dr. med. G. Reinhardt) University of Ulm and

\section{W. Arnold}

Institute of Forensic Medicine (Direktor: Prof. Dr. med. W. Janssen) University of Hamburg

(Received March 24/August 28, 1989)

\begin{abstract}
Summary: Results of radioimmunological and mass-spectrometric tests for morphine in human hair samples, conducted independently in two separate laboratories, were compared. A large degree of qualitative and quantitative parity was observed for the two methods at morphine levels above $1000 \mu \mathrm{g} / \mathrm{kg}$. Due to the variation of results at levels below $1000 \mu \mathrm{g} / \mathrm{kg}$, more GC-MS tests are necessary as a safeguard. Additional GC/MS analyses of the same samples showed that discrepancies between the results of the two methods are not necessarily due to a variable response to the analyte. The results of the GC/MS examinations showed that it is also possible to distinguish between heroin and codeine addicts.
\end{abstract}

\section{Introduction}

The detection of various toxic metals in human hair and nails has been possible for many decades, and recently it has become possible to detect drugs. Some of the drugs so far analysed in hair are morphine $(1-13)$, amphetamine $(14,15)$, barbiturates $(3-6)$, cocaine $(16)$, methaqualone $(3-5,17)$ and phencyclidine $(18,19)$.

Only recently, the detection of chloroquine was reported, after its toxic and therapeutical administration, as well as after chronic abuse (20). As in earlier studies with other drugs, it was noted that the amounts of the antimalarial drug recorded in individual hair sections correlated clearly with chloroquine dosages taken in the corresponding period. In one patient this lasted up to one year after administration. Until now the question of location and type of binding of organic substances in the hair matrix has still to be solved. In animal studies, the deposition of fluorescein in the endocuticula and mark channel of hair has been observed (21).

The aim of the study was to examine the reliability of statements regarding the abuse of heroin, morphine or codeine, using each individual method. We also wished to test the accuracy and precision of the radioimmunological and the mass-spectrometric methods, and to determine whether it is possible to differentiate between heroin/morphine consumption and codeine abuse, and whether it is possible to distinguish between heroin and codeine abuse. It must be noted that a small amount of morphine is produced from codeine by metabolic demethylation. Previous studies showed that $5-10$ percent of the codeine consumed is demethylated. 


\section{Materials and Methods}

Materials for examination

A total of $50-100$ hair samples were available, a sufficently large quantity for comparative purposes. These hair samples were cut into 1,2 or $3 \mathrm{~cm}$ segments, starting at the root end, and were then separated into parallel portions. Samples (50 $\mathrm{mg}$ ) of each hair sample were weighed and washed with acetone, then with water, once again with acetone and finally dried. In this way they could be examined radioimmunologically as well as with GC/MS. The tests were conducted in two separate laboratories.

\section{Radioimmunological method}

For the RIA analysis the specific morphine kit of the Diagnostic Product Corporation (DPC) was used exclusively. This kit is 400 times (now 1000 times) more sensitive to morphine than codeine. The individual samples are placed in long, heat resistant glass centrifuge tubes. After the addition of $1 \mathrm{ml} 1 \mathrm{~mol} / \mathrm{l}$ $\mathrm{NaOH}$ the sample is carefully boiled until the hair substance is destroyed, taking precautions to avoid vapour loss. After cooling the solution is neutralized with $1 \mathrm{ml} 1 \mathrm{~mol} / 1 \mathrm{HCl}$, taking care that the $\mathrm{pH}$ value lies between $\mathrm{pH} 6.5$ and 7.5. Deviations from these values may lead to a denaturation or damaging of the antiserum and misleading positive results.

The alkaline hydrolysis releases the morphine from the protein of the hair. Each determination should be carried out 2 or 3 times. For the construction of the standard curve it is necessary to carry out 3 determinations on each standard morphine solution. The radioimmunological analysis is performed according to the instructions enclosed the DPC kit. It is recommended that the kit is tested for its sensitivity and specificity by using a codeine solution with a concentration $300-400$ times higher than that of the standard morphine solution. If the kit shows the correct specificity, the response to the codeine and morphine test solutions should then be similar. To take account of the dilution factor, the determined quantity of morphine is multiplied by 40 .

\section{GC/MS method}

The individual hair portions are heated for a short time with $3 \mathrm{ml} 30 \mathrm{~g} / \mathrm{l} \mathrm{NaOH}$ in an evaporator until the material disintegrates. The sample is then hydrolysed for 30 minutes with $5 \mathrm{ml}$ $25 \% \mathrm{HCl}$ at $100^{\circ} \mathrm{C}$. After cooling, a drop of a mixture of octanol/ethyl acetate $(1+9$ by vol.) is added, then solid $\mathrm{NaHCO}_{3}$ until a pH value of $8-9$ is attained. The solution is adjusted to $20 \mathrm{ml}$ with glycylglycine buffer (pH 8.5), then extracted with a mixture of toluene $/ n$-butanol $(7+3$ by vol. $)$ by an Extrelut column (Merck-Darmstadt). This is followed by reextraction with $10 \mathrm{ml} 0.1 \mathrm{~mol} / 1 \mathrm{H}_{2} \mathrm{SO}_{4}$ by shaking for 5 minutes. The aqueous phase is then shaken for 5 minutes with $10 \mathrm{ml} n$-hexane and readjusted to $\mathrm{pH} 8-9$ with $\mathrm{NaHCO}_{3}$. The solution is again adjusted to $20 \mathrm{ml}$ with glycylglycine buffer and extracted with dichloromethane/propanol $(9+1$ by vol.). The organic phase is then evaporated under a nitrogen stream and the residue is dried for approximately 12 hours over silica gel. After adding $100 \mu \mathrm{l}$ heptafluorobutyric acid anhydride the samples are derivatized at $65^{\circ} \mathrm{C}$. Using a stream of nitrogen, the samples are evaporated until they are odourless, then dissolved in $20 \mu \mathrm{l}$ ethyl acetate and mixed with $1 \mu \mathrm{l}$ derivatized levallorphane $(2.5 \mathrm{mg} / \mathrm{l})$ as an internal standard.

For the GC/MS analysis, $5 \mu \mathrm{l}$ are injected without splitting into a GC/MS Hewlett Packard $5995 \mathrm{~A}$ at $60^{\circ} \mathrm{C}$ on an Ultra 2 column (cross-linked $5 \%$ phenylmethylsilicone, $25 \mathrm{~m}, 0.32 \mathrm{~mm}$ I.D., $0.52 \mu \mathrm{m}$ film) and analysed from 250 to $280^{\circ} \mathrm{C}$ programmed at $5^{\circ} \mathrm{C} /$ minute. Quantitative measurements are made at $\mathrm{m} / \mathrm{u}=246$ for morphine heptafluorobutyrate, at $\mathrm{m} / \mathrm{u}=295$ for codeine heptafluorobutyrate, and at $\mathrm{m} / \mathrm{u}=479$ for levallorphane which is used as an internal standard.

\section{Results}

\section{Comparison of methods}

Figure 1 shows the RIA and GC/MS results on 50 different hair samples. The RIA values are on the $y$ axis and the GC/MS values on the $\mathrm{x}$-axis. The gradient is 0.91 , i.e. the values are on average somewhat higher, especially at concentrations under $1000 \mu \mathrm{g} / \mathrm{kg}$. Using the radioimmunological method, some samples showed values of $200-300 \mu \mathrm{g} / \mathrm{kg}$, but by GC/MS only a few of these samples showed values over 100 $\mu \mathrm{g} / \mathrm{kg}$.

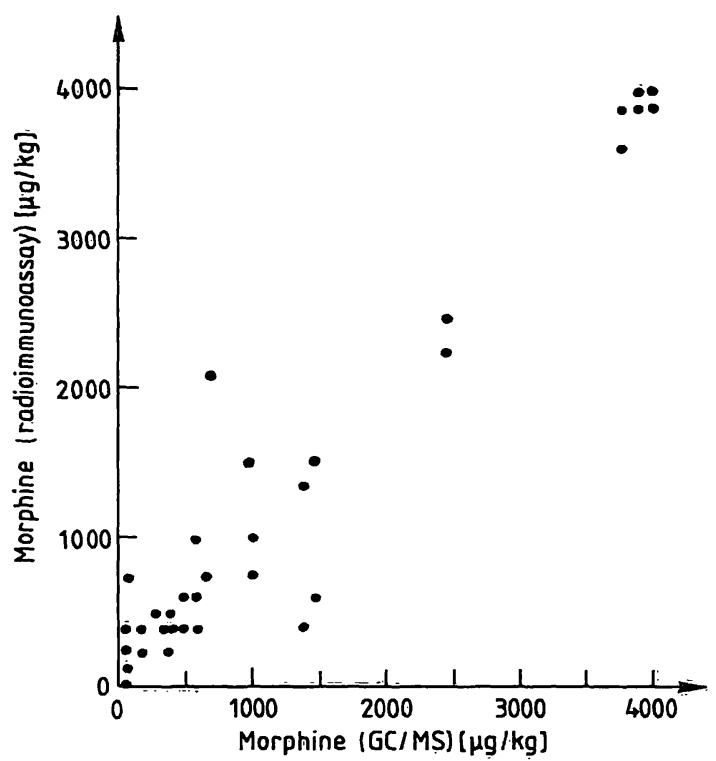

Fig. 1. Morphine concentrations in hair measured by GC/MS and RIA.

\section{Quality assessment and typical con-} centrations

Attached are a few figures, specially selected from the 50 cases which were examined. In figure 2 it can be seen that the addicts in question consumed, very probably, only large quantities of heroin, and that this heroin was only slightly contaminated with acetylcodeine. The relatively low codeine levels also support this statement, although the additional ingestion of small amounts of codeine cannot be excluded.

Figure 3 illustrates a pronounced abuse of codeine. In this case only small amounts of morphine, which were certainly formed by demethylation of the ingested codeine, were found over the whole length of the hair. The results shown in figure 4 would indicate that the subject in question initially consumed a moderate amount of heroin over a long period, and that a significant amount of codeine was simultaneously consumed as a substitute drug. In court this interpretation of the findings was confirmed without reservation by the subject standing trịal. 


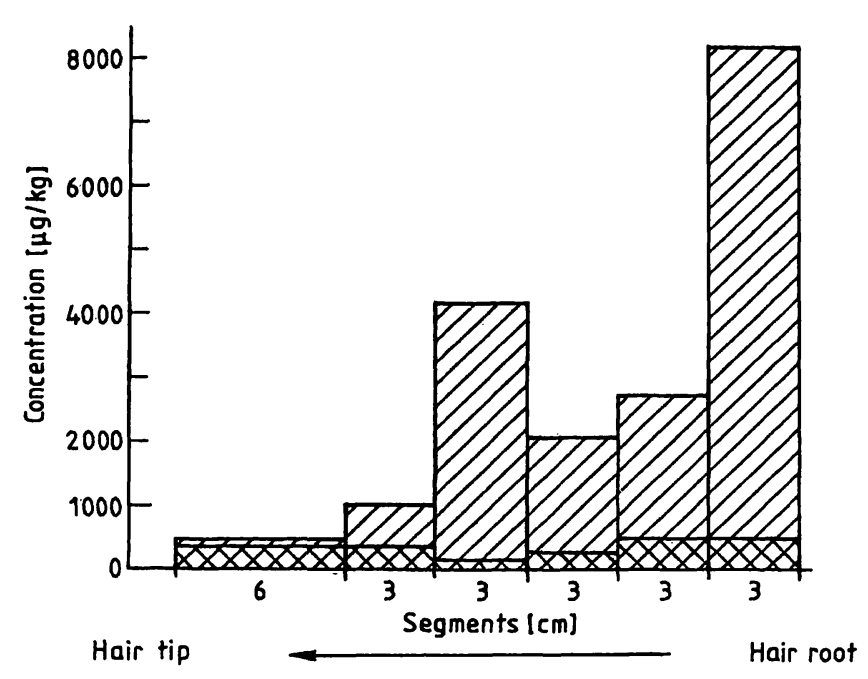

Fig. 2. Tpyical concentrations of morphine and codeine in hair after heroin abuse over a long period (with GC/MS). $\square$ morphine $\square$ codeine

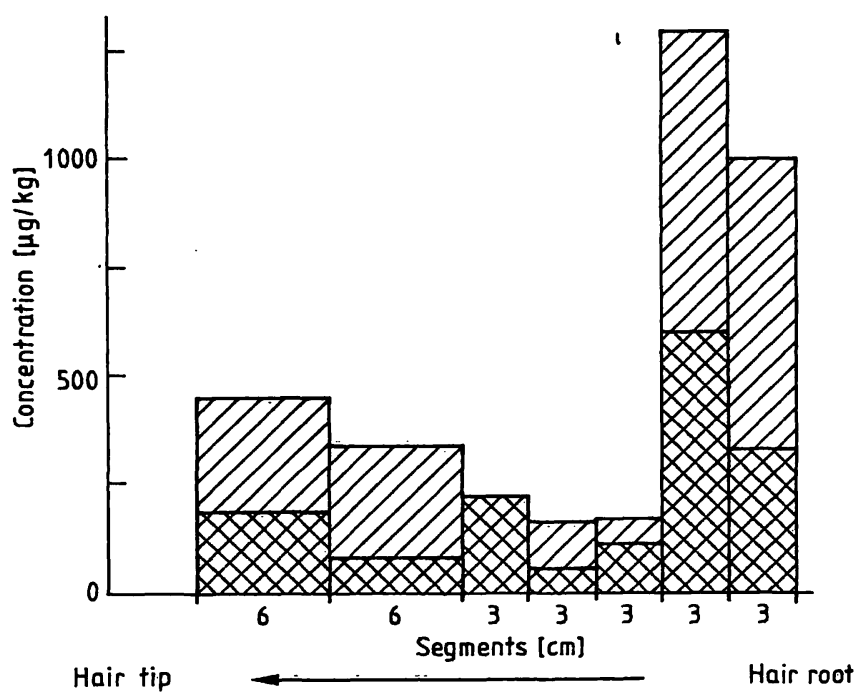

Fig. 3. Typical concentrations of morphine and codeine in hair after codeine abuse (with GC/MS).

morphine $\mathbb{\nabla}$ codeine

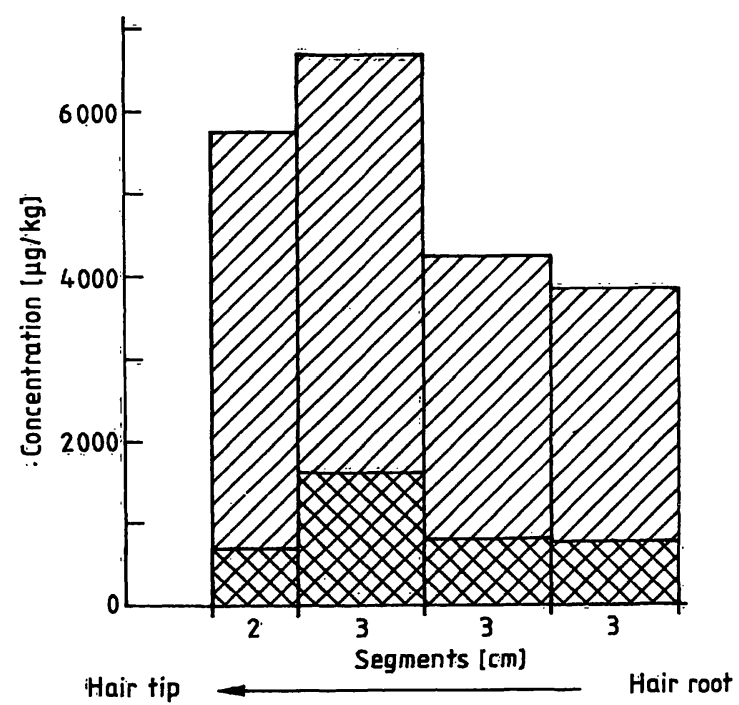

Fig. 4. Concentrations of morphine and codeine after combined consumption of heroin and codeine (with GC/ MS).

$\square$ morphine $\mathbb{Q}$ codeine

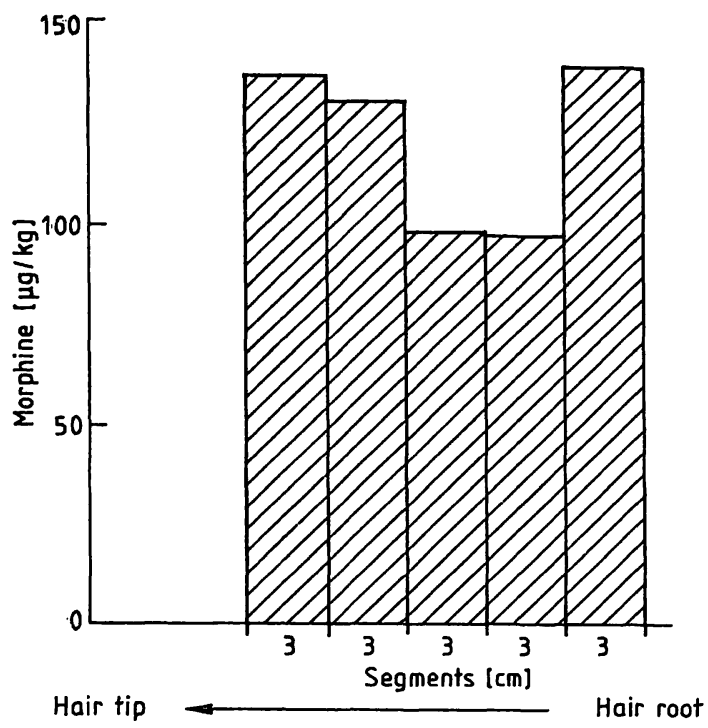

Fig. 5. Concentration of morphine in hair after intake of a small quantity of heroin or tea prepared from poppy capsules (with GC/MS).

Figure 5 illustrates a problematic case. Here very low morphine contents were recorded, mostly under 100 $\mu \mathrm{g} / \mathrm{kg}$. These levels would have been regarded as insignificant, if some of the levels had not risen to 150 $\mu \mathrm{g} / \mathrm{kg}$. Since no codeine was found - in this case the detection limit of GC/MS was set at $20 \mu \mathrm{g} / \mathrm{kg}$ - it was assumed that the heroin consumption was very small. The accused testified that he often made a tea of poppy capsules. This possibility cannot be excluded.

It can be assumed that the mode of deposition of organic drugs and narcotics in hair is similar to that of inorganic substances. Some evidence has been obtained topographically, indicating that other organic substances are possibly deposited in the endocuticula and mark channel, as shown in animal experiments with fluorescein (21). The strength and type of protein bond is, however, still unknown.

\section{Discussion}

From the results obtained so far, it can be assumed that the morphine levels detected in hair reflect the morphine or heroin levels absorbed by the body. In this connection and, above all, when the 3 different hair growth phases are taken into account, it may be assumed, that the concentration of a drug in the first months following ingestion is higher than after 6 months or even longer, as shown in the above-mentioned chloroquine poisoning case (20). Theoretically the concentration curve after a single intake is steeper and higher in the first months than in the hair samples, which have grown for several months. This is illustrated in figure 6. A particular problem in the detection of opiates is evaluating whether observed mor- 

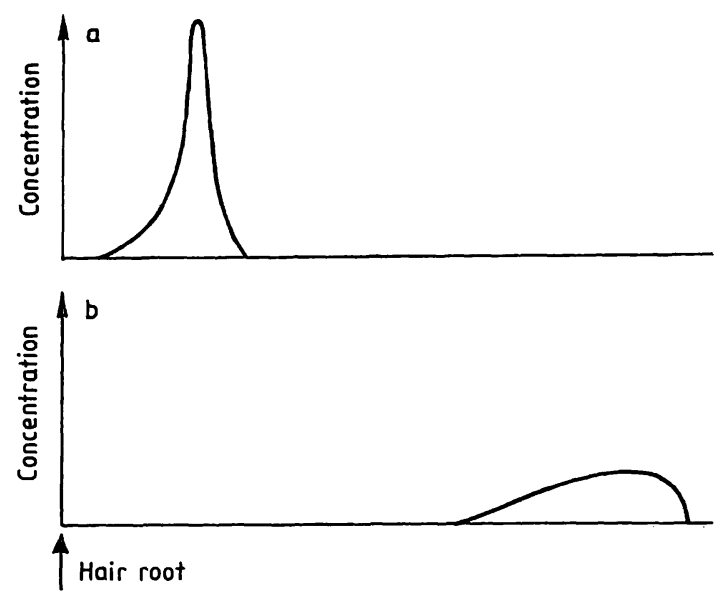

Fig. 6. Schematic illustration of the temporal distribution of drugs in hair after a single dose.

a) a few days after intake

b) several months after intake

phine concentration has resulted from heroin/morphine consumption or from a misuse of medication containing codeine.

On the hand, small amounts of morphine in the body result by demethylation of codeine, and on the other hand, almost all illegally sold heroin contains acetylcodeine as an impurity which is quickly deacetylated to codeine after intake. In both cases, codeine and morphine exist and are detectable in most cases in hair samples. For this reason, in addition to the specific RIA (DPC) analysis, both opiates must be tested for with the non-specific RIA kit of La Roche, or an additional analysis must be performed, using GC/MS to separate codeine and morphine. Success with radioimmunological differentiation with the specific and non-specific kits can only be guaranteed for levels above $1000 \mu \mathrm{g} / \mathrm{kg}$. Even though the DPC kit is 400 times (now 1000 times) more sensitive to morphine than codeine, the possibility cannot be excluded that the DPC kit indicates levels which are too high when morphine and codeine are mixed.

A comparison of the levels from radioimmunological and GC/MS studies shows that for forensic purposes, if the positive RIA levels for morphine obtained with the morphine-specific DPC kit are not very high, it is important to perform, a GC/MS analysis as a safeguard. If a DPC kit examination is obviously negative and if there is no further tangible evidence such as prick marks, conspicuous behaviour etc., then it must be assumed that the individual did not consume any significant amounts of opium alkaloids during the timeframe under examination.

If the levels measured by the DPC kit are over 1000 $\mu \mathrm{g} / \mathrm{kg}$, then the radioimmunological findings which clearly indicate heroin abuse are confirmed. This has already been discussed in another study $(4,5)$.
In spite of the use of 2 methods it is, however, not always possible to make a statement with absolute certainty about the form of ingestion. If the morphine level is clearly higher than the codeine level in the examined hair sample, heroin or morphine abuse is highly probable (22). The codeine could result from heroin contaminated with acetylcodeine, which is metabolically deacetylated and therefore detected as codeine. If the morphine and codeine concentrations are equal, or if the morphine level is only marginally higher than the codeine level, then it may be assumed that both alkaloids have been ingested (22). Where the level is under $500 \mu \mathrm{g} / \mathrm{kg}$ it cannot be said with certainty whether this concentration results from a morphine/heroin ingestion or codeine abuse (22); in such cases, even GC/MS measurements on hair samples in the same growth phase can also give very different results. This can be explained on the one hand by irregular growth rates which have already be mentioned, but also because the absolute levels of the examinations are on a picogram scale and therefore near the detection limit.

The present studies revealed differences between the results of radioimmunological and mass-spectrometrical analyses, even after repeated GC/MS examinations of parallel strands of hair. Such discrepancies can have different causes. It cannot be guaranteed that all the hair portions used in the radioimmunological and the GC/MS examinations were identical to the millimetre. Furthermore, variations may be due to the different growth phases of hair. As a rule, hair grows for 4 to 6 years (anagen phase) and then stagnates for a period of a few months (catagen phase) before it falls out. Normally only $85 \%$ of hairs are in the growth phase at a given time. After several months, some of the morphine can therefore be located at a totally different site from the main area of deposition. In addition an irregular distribution of morphine may also be caused by other disturbances to hair growth, such as medical complaints, possibly of a hormonal nature.

In conclusion, the results of the tests on a total of 50 hair samples can be summarized as follows. In 2 different laboratories independent from one another, radioimmunological and GC/MS examinations showed a large degree of quantitative parity for both methods for levels of morphine above $1000 \mu \mathrm{g} / \mathrm{kg}$. Considerable differences between the methods were found for levels below $1000 \mu \mathrm{g} / \mathrm{kg}$. In such cases, the results should be supported by a second method, especially when investigations have failed to produce sufficient evidence of drug abuse. 


\section{References}

1. Arnold, W. (1980) The Estimation of Medicaments in Human Hair. Vortrag Satellite Conference to the 8th Intern. Conference on Alcohol, Drugs and Traffic Safety. Umea, Sweden, Juni 1980.

2. Arnold, W. (1982) Radioimmunologische Untersuchungen im Rahmen der Drogenszene. In: Beiträge zur Diagnose und Therapie akuter Vergiftungen (Müller, R. K., ed.) Akademie Verlag Leipzig 1982.

3. Arnold, W. (1984) Modern Trends of Chemical Analysis in the Drug-Scene. In: Topics in Forensic and Analytical Toxicology (Maes, R. A. A., ed.) Elsevier Science Publisher BV Amsterdam 1984, pp. $45-51$

4. Arnold, W. \& Püschel, K. (1984) Haare als wichtiges Untersuchungsmaterial in der Rechtsmedizin. Ann. Univ. Sarav. Med. Suppl. 4, 76-78.

5. Arnold, W. (1987) Radioimmunological Hair Analysis for Narcotics and Substitutes. J. Clin. Chem. Clin. Biochem. 25, 753-757.

6. Arnold, W. \& Püschel, K. (1980) Toxicological Findings after Abuse of Narcotics. In: Toxicological Aspects (Kovatsis, A., ed.) Verl. Technika Studio, Thessaloniki Greece 1980, pp. $248-251$.

7. Arnold, W. \& Püschel, K. (1980) Besondere Aspekte radioimmunologischer Untersuchungsbefunde bei Rauschgifttodesfällen. Zentralbl. Ges. Rechtsmed. 20, 13-14.

8. Arnold, W. \& Püschel, K. (1981) Experimental Studies on Hair as an Indicator of Past or Present Drug Use. J. Forens. Sci. Soc. 21, 82.

9. Arnold, W., Teichner, M. \& Püschel, K. (1982) Chemischtoxikologische Befunde bei 100 Rauschgifttodesfällen. In: Proc. XII. Congr. Intern. Akad. Gericht. Soz. Med., Band 2, pp. 743-747. Verl. H. Egermann, Wien.

10. Arnold, W. \& Bohn, G. (1987) Hautanhangsgebilde, ein besonderes Asservat für die forensische Diagnostik und Begutachtung. Beitr. Gerichtl. Med. 45, 261-267.

11. Baumgartner, A. M., Jones, P. F., Baumgartner, W. A. \& Black, C. T. (1979) Radioimmunoassay of Hair for Determination of Opiate Abuse. J. Nucl. Med. 20, 748-752.
12. Püschel, K., Thomasch, P. \& Arnold, W. (1983) Opiate Levels in Hair. Forens. Sci. Intern. 21, 181-186.

13. Sachs, H. \& Brunner, B. (1986) Opiatuntersuchungen in Haaren mit GC/MS. Beitr. Gerichtl. Med. 44, 281-288.

14. N.N. (1984) Monitoring of Substance Abuse through Hair Analysis: A Breakthrough in Medical and Forensic Science. Janus Foundation - Los Angeles. Research Report, December 1984.

15. Suzuki, O., Hattori, H. \& Asano, M. (1984) Detection of Methamphetamine and Amphetamine in a Single Human Hair by Gaschromatography/Chemical Ionisation MassSpectrometry. J. Forens. Sci. 29, 611-617.

16. Baumgartner, W. A., Black, C. T., Jones, P. F. \& Blahd, W. H. (1982) Radioimmunoassay of Cocaine in Hair. J. Nucl. Med. 23, 790-792.

17. Radloff, H. (1983) Haaruntersuchungen auf Methaqualon mittels Radioimmunoassay. Dissertation Med. Fachbereich, Universität Hamburg.

18. Baumgartner, A. M., Jones, P. F. \& Black, C. T. (1981) Detection of Phencyclidine in Hair. J. Forens. Sci. 26, 576581.

19. Skramek, J. J., Baumgartner, W. A., Tallos, J., Ahrens, T. N., Meiser, J. F. \& Blahd, W. H. (1985) Hair Analysis for Detection of Phencyclidine in Newly Admitted Psychiatric Patients (in press) Personal communication.

20. Ochsendorf, F. R., Runne, U., Schöfer, H., Schmidt, K. \& Raudonat, H. W. (1988) Sequentielle Chloroquin-Bestimmung im menschlichen Haar bei toxischer/therapeutischer Dosierung. Korrelation zur Dosis und Therapiedauer. Zentralbl. Rechtsmed. 31,866-867.

21. Pötsch, L. \& Wolf, G. (1988) Zum Nachweis organischer Substanzen im Haar. Zentralbl. Rechtsmed. 31, 910.

22. Arnold, W. (1986) Kritische Bemerkungen zum Nachweis organischer Arzneimittel in Kopfhaaren. Toxichem + Krimtech. Issue 42, 12-13.

Prof. Dr. med. Dr. rer. nat. Wolfgang Arnold Eckerkamp 96

D-2000 Hamburg 65 
